\title{
A recuperação da informação visual baseada na localização e nas características visuais dos objetos
}

César Alexis Galera. Universidade de São Paulo (Ribeirão Preto). Luísa Superbia Guimarães. Universidade de São Paulo (Ribeirão Preto). Joaquim Carlos Rossini. Universidade Federal de Uberlândia. Jeanny Joana Rodrigues Alves de Santana. Universidade Federal de Uberlândia.

\section{Resumo}

Nós investigamos a recuperação de características visuais (cor, forma) de um objeto armazenado na memória de trabalho visual. Dicas retroativas, espaciais ou baseadas nas características visuais do objeto memorizado, foram apresentadas em uma tarefa de reconhecimento visual. Dicas retroativas espaciais sinalizavam o local ora da cor, ora da forma a ser reconhecida; a dica de forma sinalizava a cor a ser reconhecida; a dica de cor sinalizava a forma. Os resultados mostram que a dica espacial proporciona um ganho no reconhecimento da cor, mas não da forma. Nem a cor nem a forma proporcionam ganhos no reconhecimento, respectivamente, da forma ou da cor. Nossos resultados sugerem que a informação espacial é mais relevante para a recuperação da informação memorizada do que a informação visual. Discutimos o papel da atenção no processo de recuperação e a importância do buffer visual como sistema da memória de trabalho visual.

Palavras-chave: memória operacional; memória de curto prazo; imagem mental; atenção visual.

\begin{abstract}
The retrieval of visual information based on the location and visual features of objects. We investigate the retrieval of visual characteristics (color, form) of an object stored in visual working memory. Retro-cues based on location or on memorized characteristics were presented in a visual recognition task. Location retro-cues pointed out the place where the to be recognized feature (color or form) was at the memorized scene; color retro-cues cued the to be recognized form; form retro-cues cued color. Results show that spatial retro-cue allows a gain in color recognition but not in form recognition. Neither the color nor the form retro-cues provide significant improvement in recognition of form or color, respectively. Our results suggest that spatial information is more relevant to the recovery of the memorized information than the visual characteristics. We discuss the role of attention in the recovery process and the importance of the visual buffer as a visual working memory system.
\end{abstract}

Keywords: working memory; short-term memory; mental imagery; visual attention.

\section{Resumen}

La recuperación de la información visual basada en la localización y en las características visuales de los objetos. Nosotros investigamos la recuperación de características visuales (color, forma) de un objeto almacenado en la memoria de trabajo visual. Pistas retroactivas, espaciales o embazadas en características del objeto memorizado, fueron presentadas en una tarea de reconocimiento visual. Pistas espaciales señalaron el sitio del color, o de la forma a ser reconocida; la pista de forma señaló el color y la pista de color señaló la forma a ser reconocida. Los resultados muestran que las pistas espaciales proporcionan un gaño en lo reconocimiento del color, pero no de forma. Ni el color ni la forma proporcionan beneficios en el reconocimiento, respectivamente, de la forma o del color. Nuestros resultados sugieren que la información espacial es más relevante para la recuperación que la información visual. Discutimos el rol de la atención en la recuperación y la importancia del visual buffer como un sistema de la memoria de trabajo visual.

Palabras clave: memoria operacional; memoria de corto plazo; imágenes mentales; atención visual. 
No modelo de memória de trabalho, o sistema responsável pelo armazenamento da informação não-verbal, o esboço visuoespacial, foi concebido como um armazenador com múltiplas funções. Ele é capaz de armazenar e integrar as informações visual e espacial em representações visuoespaciais unitárias, além de ser também responsável pela geração e manipulação das imagens mentais (Baddeley, 1986, 2007). Logie (1995) redistribuiu essas funções em dois armazenadores, o visual cache e o inner scribe. O visual cache é responsável pelo armazenamento de informações visuais estáticas, tais como cores, texturas e formas presentes em uma, e apenas uma, cena. O inner scribe tem funções mais complexas: é responsável pelo armazenamento das relações espaciais entre os objetos da cena, pelo armazenamento de sequências de eventos no espaço visual e pela recitação do conteúdo armazenado no visual cache. Neste artigo, usaremos o termo "espacial" para nos referirmos a dicas ou informações atinentes à localização no espaço ou posicionamento relativo entre objetos na cena; o termo "visual" será usado daqui em diante para se referir a dicas baseadas nas características estáticas dos objetos (ou seja, aquelas que não prescindem de informações concernentes à localização no espaço ou posição relativa entre objetos na cena). A conceituação teórica das dicas será explorada mais adiante nesta introdução.

As representações mantidas no visual cache não são representações realmente visuais, mas representações abstratas, que podem ter sido adquiridas tanto através da visão como do tato ou de descrições verbais e interpretadas com base no conhecimento de longo prazo (Logie, 2003). Estas representações conteriam as informações necessárias à reconstrução da memória visual em termos de imagens mentais visuais. No entanto, de acordo com Logie (2011), a imagem visual não é uma função da memória de trabalho visual, mas do sistema executivo central.

O modelo de memória de trabalho visual (MTV) proposto por Logie $(1995 ; 2003 ; 2011)$ contribuiu para compreensão de alguns pontos não especificados no esboço visuoespacial (Baddeley, 1986; 2007), mas deixou em aberto algumas questões importantes, entre elas a interação entre o armazenamento da informação visual em um sistema de memória passivo e a capacidade da manipulação consciente da imagem mental. As evidências sugerem que o armazenamento da informação visual e a representação dessa informação na forma de uma imagem mental são funções distintas (Borst, Niven, \&
Logie, 2012; Pearson, 2001; Quinn \& McConnell, 1996) mas, sem dúvida, relacionadas. Antes que possa ser inspecionada e manipulada de forma consciente como uma imagem mental, a representação dos aspectos visuais de um objeto memorizado - seja na memória de longo prazo, seja no visual cache - deve ser recuperada para um estado ativo, no qual é privilegiada em relação às representações de outros objetos memorizados, mas não disponíveis ao foco da atenção naquele momento (Oberauer, 2003).

Nós temos investigado o processo de recuperação da informação visual armazenada no visual cache e as restrições que esse processo de recuperação faz à arquitetura da memória de trabalho visual (Ferreira, Pucci, \& Galera, 2014; Galera \& Quinn, 2014). Embora algumas propostas teóricas considerem que a imagem mental é sustentada pelo foco da atenção ou, de forma equivalente, que é uma função do executivo central (Cowan, 2005; Logie, 2003; 2011), nós consideramos que a imagem mental, além de ser dependente do executivo central, necessita de um meio de representação que a sustente, em um estado ativo, enquanto está sob o foco da atenção. O buffer visual seria tal meio de representação (Galera \& Quinn, 2014; Pearson, 2001; Quinn 2012).

No modelo computacional proposto por Kosslyn (1994), o buffer visual agrupa áreas do córtex visual primário em uma estrutura funcional única. Uma grande parte dessas áreas corticais apresenta uma organização topográfica, de forma que padrões de atividades nessas áreas reproduzem a organização espacial projetada pelos estímulos nas retinas. Estudos realizados com técnicas de obtenção de imagens cerebrais têm sugerido que $2 / 3$ das áreas identificadas com o buffer visual seriam ativadas tanto durante tarefas de imaginação visual como em tarefas que exigem apenas a observação de padrões visuais (Kosslyn, Ganis, \& Thompson, 2001). Todavia, o buffer visual contém mais informações do que pode ser processado simultaneamente, o que exige uma janela atentiva capaz de selecionar algumas de suas regiões para processar em detalhes as informações ali relacionadas.

De acordo com esse modelo, a janela da atenção pode ser mudada de uma região a outra do buffer, ou para diferentes objetos. É através da janela da atenção que a informação visual vinda do ambiente é codificada em termos de suas características espaciais e visuais. As características espaciais são codificadas, independentemente das características visuais, em um 
sistema de processamento das propriedades espaciais (spatial properties processing). As características visuais são codificadas, independentemente de suas características espaciais, em um sistema de processamento das propriedades dos objetos (object-properties-processing). A geração da imagem mental de um objeto exige a recuperação da informação armazenada no sistema de processamento das propriedades dos objetos para uma área topograficamente organizada, o buffer visual. Isto é feito com base na associação entre o objeto e localização armazenada na memória associativa de longo prazo.

As evidências acerca do sistema buffer visual como um componente que sustenta a representação visual em estado ativo são, em grande parte, originadas de estudos que avaliam a orientação da atenção para a representação memorizada (Albers, Kok, Toni, Dijkerman, \& Langue, 2013; Harrison \& Tong, 2009, por exemplo). Nobre e colaboradores (Griffin \& Nobre, 2003; Lepsien \& Nobre, 2006) têm adotado o paradigma de dicas retroativas para investigar a orientação da atenção na memória de trabalho. Nestes estudos, o participante memoriza uma cena formada por um ou mais objetos (formas visuais coloridas, faces ou cenas visuais). Ao final do intervalo de retenção, antes que seja apresentado o estímulo teste, uma dica simbólica (uma seta) aponta para o local da cena em que foi apresentado o estímulo que pode ser apresentado como estímulo teste (por exemplo, um objeto colorido). Logo em seguida à dica, o estímulo teste é apresentado e o participante deve decidir se este estava ou não presente entre os estímulos memorizados. De forma diferente do paradigma de Sperling (1960), o intervalo entre o display memorizado e a apresentação da dica retroativa (em torno de $2500 \mathrm{~ms}$ ) é longo o suficiente para garantir que os estímulos memorizados não estejam mais disponíveis na memória icônica.

O paradigma de dicas retroativas difere, também, do paradigma de dicas preditivas de Posner (1980) - no qual o participante é informado a priori sobre o local em que será apresentado o estímulo relevante a ser memorizado. O paradigma de Griffin e Nobre (2003) utiliza uma dica a posteriori que informa o local em que o estímulo teste foi apresentado, depois de os estímulos não estarem mais disponíveis à percepção. As dicas preditivas de Posner, portanto, guiam a atenção do participante para o local do espaço percebido em que aparecerá o estímulo relevante no futuro. As dicas retroativas, por sua vez, guiam a atenção do participante para um local no espaço memorizado, ou seja, onde o estímulo relevante se encontra na representação mental da cena memorizada.

Os resultados obtidos por Griffin e Nobre (2003) mostram que os participantes são mais rápidos e mais precisos nas provas com dicas válidas - aquelas que indicam o local previamente ocupado pelo estímulo teste, do que nas provas com dicas neutras, nas quais nenhum local é indicado. Este padrão de resultados foi o mesmo para dicas preditivas e retroativas, sugerindo que a orientação da atenção para uma representação memorizada do espaço produziu resultados praticamente idênticos àqueles obtidos com a orientação da atenção para as posições no espaço percebido. Segundo Lepsien e Nobre (2006), quando a dica retroativa é apresentada, o participante recupera a informação da memória de trabalho ou da memória de longo prazo e a mantém em um estado ativo até que o estímulo teste seja apresentado e uma decisão possa ser tomada (p. 28). Nós consideramos que este processo de recuperação é análogo ao processo de recuperação da informação na tarefa de memória baseada em imagens mentais (peg-word). Nessa tarefa uma palavra/imagem serve como dica para a recuperação de uma palavra associada (Logie \& Marcheti, 1991; Quinn \& MacConell, 2006).

Além das evidências de orientação da atenção para a memória baseada em dicas espaciais (Griffin \& Nobre, 2003; Lepsien \& Nobre, 2006), alguns estudos também têm mostrado resultados semelhantes quando a atenção é orientada para categorias de objetos visuais memorizados. Por exemplo, Lepsien e Nobre (2006) avaliaram o papel da atenção orientada por uma dica retroativa para uma das categorias de objetos memorizados (uma face ou uma cena) armazenadas na memória de trabalho visual. As bases neurais deste fenômeno foram avaliadas por meio de imagens por ressonância magnética funcional (fMRI) aliadas a dados comportamentais de tempo de reação e acurácia da memória. Os resultados indicaram que a dica retroativa é seguida por um aumento da ativação de áreas cerebrais envolvidas com o processamento das informações indicadas pela dica, e esta ativação foi associada a uma melhora no desempenho de recordação na memória de trabalho. Os autores interpretam estes dados como uma evidência de que a atenção modula a atividade relacionada à manutenção dos objetos da categoria indicada na memória de trabalho, independente da categoria do objeto. Além disso, os resultados comportamentais mostram que os participantes foram capazes de orientar a atenção seletivamente 
para categorias de objetos mantidos na memória, o que resulta num ganho significativo no processo de recuperação.

Esta capacidade de seleção baseada em categorias foi confirmada por Lepsien, Thornton e Nobre (2011), que sugerem que as dicas retroativas atuam por meio de um mecanismo top-down que modula o controle atentivo na memória, à semelhança do que ocorre na seleção da informação em tarefas perceptivas. Este mecanismo inclui a atividade de estruturas cerebrais das regiões parietais e frontais, que resultam em sinais neurais de regulação baseados na prioridade da informação. Desta forma, a dica retroativa desencadeia um sistema de priorização da informação (do tipo top-down) que favorece o desempenho da memória, seja porque permite a recuperação da informação memorizada (Lepsien e Nobre, 2006), seja porque fornece a informação sobre a relevância de um determinado item para sua recuperação subsequente (Gazzaley \& Nobre, 2012). Peters, Kaiser, Rahm e Bledovski (2015) também encontraram evidências de que focalizar a atenção em um objeto mantido na memória prioriza o processamento das características presentes no objeto atendido, em detrimento das características presentes em outros objetos.

A orientação da atenção para as características visuais que definem os objetos memorizados têm sido um tema recorrente de estudos, sobretudo em tarefas de busca visual. Maunsell e Treue (2006), por exemplo, sugerem que a busca visual pode ser guiada pelas características visuais específicas que definem um objeto, independentemente de sua localização espacial. Nesse caso, a atenção para uma característica visual modula sinais neuronais em uma série de áreas do córtex visual e permitem maior eficiência na detecção do alvo, independentemente do local em que este é apresentado. De acordo com Carrasco (2011), evidências neurofisiológicas e psicofísicas mostram que a atenção baseada em características visuais privilegia o processamento da característica atendida em detrimento de características não atendidas ou irrelevantes. Evidentemente, selecionar os objetos no ambiente em função de características visuais específicas, independente dos locais que os objetos ocupam, tem um valor adaptativo. É exatamente o que acontece, por exemplo, quando se procura por uma fruta amarela em um arbusto, ou por um livro com a capa azul na estante.

No estudo da memória visual, o uso de dicas retroativas baseadas em características visuais é ainda incipiente. Em um dos poucos estudos publicados, $\mathrm{Li}$ e Saiki (2015) investigaram o efeito de dicas preditivas e retroativas na codificação e na manutenção da informação visual memorizada. As dicas usadas pelos autores eram baseadas em características visuais conjugadas à localização espacial. Nesse estudo, a forma de um objeto é utilizada como dica para a conjunção de forma e localização; a cor é utilizada como dica para a conjunção de cor e localização; e a localização é utilizada como dica tanto para a conjunção de cor e localização como para a conjunção de forma e localização. Nessa situação, as dicas retroativas visuais baseadas na cor são tão eficientes quando dicas espaciais, mas são menos eficientes do que dicas espaciais quando os estímulos são definidos pela conjunção de cor e forma. Neste caso, forma e cor têm efeitos diferentes sobre a tarefa de detecção de mudança. Enquanto o efeito da dica retroativa de cor é menos pronunciado que o efeito da dica espacial, o efeito da dica retroativa de forma não é diferente daquele obtido com a dica espacial.

De maneira geral, os resultados obtidos por $\mathrm{Li}$ e Saiki (2015) sugerem que a modulação atentiva na memória e na percepção é mediada por mecanismos comuns quando se trata de dicas baseadas na localização espacial, mas não quando se trata de dicas baseadas na cor, o que pode refletir uma propriedade estrutural assimétrica da memória de trabalho visual. Este resultado implica em uma possível primazia da informação espacial em relação à informação visual já apontada em estudos de atenção perceptual (Treisman, 1998; Treisman \& Gelade, 1980) e também em estudos da memória visual de curto prazo (Fougnie \& Alvarez, 2011; Kondo \& Saiki, 2012; Pertzov \& Husain, 2014).

Em resumo, a literatura mostra que o armazenamento da informação visual na memória de trabalho e a geração de imagens mentais visuais parecem ocorrer em diferentes estruturas (Borst et al., 2012; Pearson, 2001; Quinn \& McConnell, 1996). A recuperação da informação da memória de trabalho para um estado ativo no qual a imagem pode ser inspecionada de forma consciente parece envolver áreas do córtex visual primário identificadas com o buffer visual (Kosslyn, 1994; Kosslyn et al., 2001). A informação sobre localização espacial proporcionada pela dica retroativa permite a recuperação da informação armazenada na memória de trabalho para um estado ativo; neste estado ativo, a informação recuperada pode ser comparada de forma mais eficiente com a informação de entrada, levando a um desempenho mais acurado e mais rápido em tarefas 
de reconhecimento (Lepsien \& Nobre, 2006). A literatura mostra ainda que a orientação da atenção em função de características visuais em tarefas de busca visual tem um papel equivalente ao da orientação baseada na localização espacial (Maunsell \& Treue, 2006).

Apesar de apontar uma assimetria na contribuição da informação espacial e da informação baseada em características na orientação da atenção na memória de trabalho, o estudo de Li e Saiki (2015) deixa em aberto uma questão relevante para a investigação da mesma. A tarefa de detecção de mudança utilizada pelos autores é baseada na conjunção das informações visual e espacial; deixando, portanto, sem resposta a questão sobre a recuperação da informação na memória de trabalho visual a despeito da contribuição da informação espacial - isto é, sem levá-la em conta. Em nosso estudo, procuramos avaliar a contribuição da orientação atentiva em função das características visuais de forma e cor, independentemente da localização espacial. Busca-se também comparar a eficácia deste processo baseado em características visuais com o processo de orientação baseado na localização espacial.

Dessa forma, a comparação da eficácia do processo de recuperação baseado em dicas espaciais e dicas baseadas em características (cor e forma) pode nos permitir conhecer melhor o processo de recuperação da informação memorizada. Nossa suposição inicial é que a recuperação da informação memorizada deve ser mais beneficiada pela dica de localização espacial, que tem um peso privilegiado no processo de alocação da atenção (Treisman \& Gormican, 1988); isto também é reconhecido no modelo de buffer visual proposto por Kosslyn (1994). Entretanto, não temos ainda conhecimentos que nos permitam avaliar a eficácia da cor para recuperar a forma e da forma para recuperar a cor.

\section{Método}

\section{Participantes}

Participaram do estudo doze universitários e dois dos autores, sendo 11 homens, com idades entre 17 e 60 anos (média de 26,4 anos), com acuidade visual normal ou corrigida para o normal.

\section{Material e Estímulos}

Foram utilizados como estímulos 64 formas geométricas coloridas, resultantes da combinação de oito formas geométricas simples (triângulo, quadrado, círculo, losango, estrela, flecha, meia-lua e cruz) e de oito cores (amarelo, azul claro, azul escuro, cinza, laranja, rosa, vermelho e verde). Os estímulos tinham aproximadamente $1 \mathrm{~cm}^{2}$ de área (40 pixels por 40 pixels), apresentados nos vértices de um quadrado imaginário, distantes $4 \mathrm{~cm}$ do ponto de fixação. $O$ ponto de fixação era uma moldura quadrada com lados de $0,5 \times 0,5 \mathrm{~cm}$ e 1 pixel de espessura. A dica de cor era uma mancha colorida do mesmo tamanho que as formas geométricas, sem forma ou contornos definidos que pudessem se assemelhar ao formato de uma das formas geométricas apresentadas anteriormente. A dica de cor neutra era uma mancha preta. A dica de forma era uma figura geométrica com as bordas apresentadas em preto e a dica de forma neutra era uma espiral apresentada em preto. Nas provas com dicas espaciais, dois lados do ponto de fixação central tornavam-se mais espessos (dois pixels), formando uma seta que apontava para uma das quatro posições ao redor do ponto de fixação. Na dica espacial neutra os quatro lados do ponto de fixação tinham a espessura de dois pixels. A Figura 1 exemplifica os tipos de dicas utilizados no experimento.

\section{Delineamento Experimental e Procedimento}

A tarefa experimental era uma tarefa de reconhecimento de item combinada ao paradigma de dicas retroativas. Os participantes observavam e deviam memorizar quatro formas geométricas coloridas e, depois de um intervalo de retenção, deveriam decidir se a forma ou a cor de um estímulo-teste correspondia a uma das formas ou a uma das cores memorizadas. A dica retroativa era apresentada ao final do intervalo de retenção, antes da apresentação do estímulo a ser reconhecido. A dica retroativa poderia ser espacial ou visual. A dica retroativa espacial informava ao participante a localização do estímulo com a dimensão relevante para a tarefa de reconhecimento (forma ou cor). A dica retroativa visual informava ao participante a cor, ou a forma, do estímulo com a dimensão relevante para a tarefa de reconhecimento, neste caso, a forma ou a cor, respectivamente. O tipo de tarefa de reconhecimento (cor ou forma) e o tipo de dica (espacial ou visual) foram manipulados entre blocos de provas. Dessa forma foram realizadas quatro condições experimentais: dica espacial para o reconhecimento da forma; dica espacial para o reconhecimento da cor; dica visual de cor para o reconhecimento da forma; e dica visual de forma para o reconhecimento da cor. 


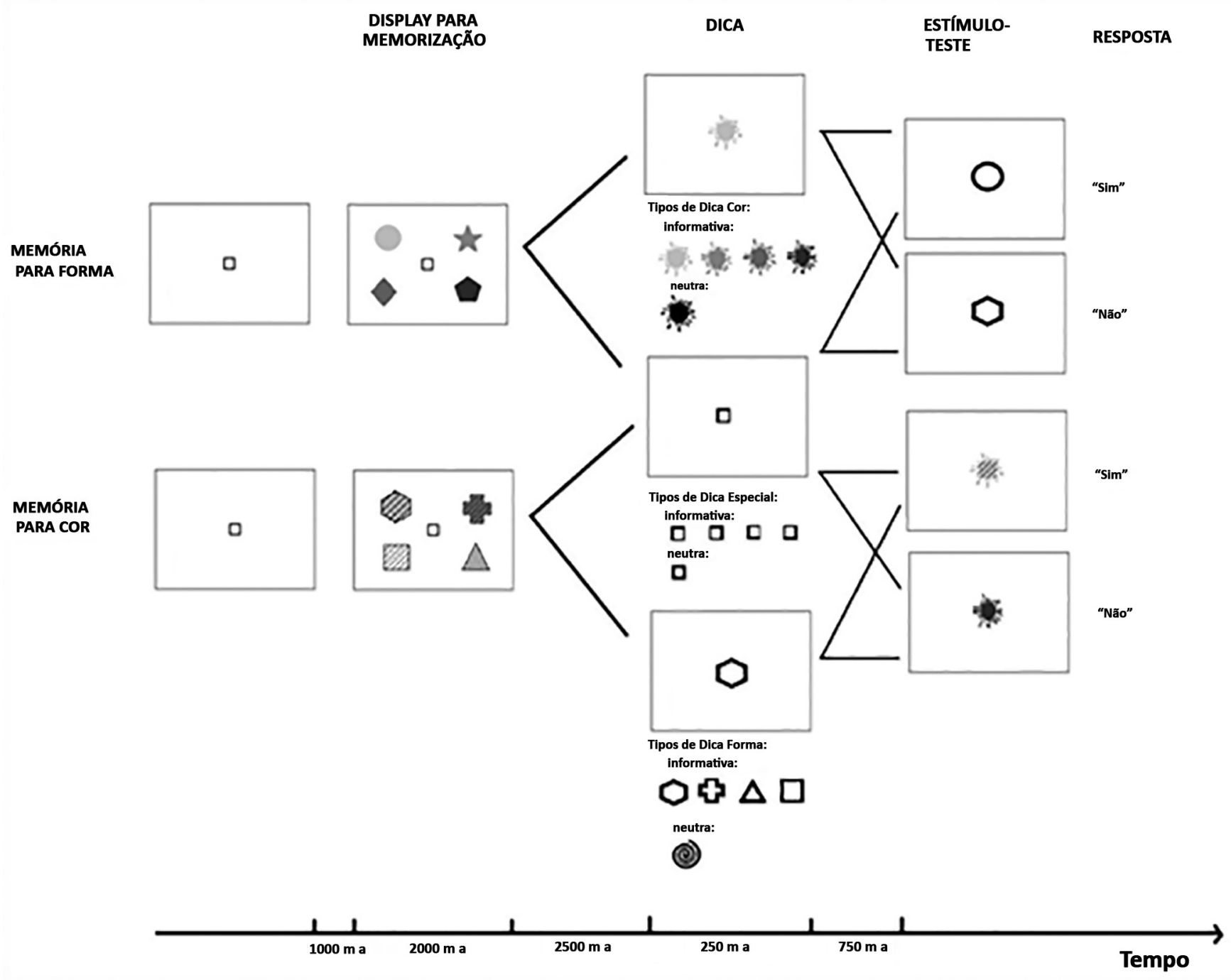

Figura 1. Representação Esquemática da Sequência de Eventos das Tarefas de Memória para Forma e para Cor, nas Condições de Dica Visual e Espacial, para Provas Positivas e Negativas. Cada Tom de Cinza e Padrão de Hachuras Representa uma Cor Diferente.

Cada prova tinha início com a apresentação do ponto de fixação, que permanecia na tela até a apresentação da dica. Os quatro estímulos a serem memorizados eram apresentados $1000 \mathrm{~ms}$ depois e permaneciam na tela por 2000ms. Depois de 2500 ms a dica era apresentada no centro da tela, sobre o ponto de fixação, e permanecia visível durante $250 \mathrm{~ms}$. O intervalo entre a dica e a apresentação do estímulo teste foi de 1000 ms. O estímulo teste era apresentado no centro da tela e permanecia visível até que o participante efetuasse sua resposta pressionando o botão esquerdo do mouse para a resposta positiva ("sim, o estímulo teste é igual a um estímulo da cena memorizada"), ou o botão direito para a resposta negativa ("não, o estímulo teste é diferente dos estímulos da cena memorizada"). A chance do estímulo teste ser igual ou diferente a um dos estímulos memorizados era de $50 \%$.
A dica retroativa era informativa em metade das provas e neutra na outra metade. Os participantes eram informados que as dicas informativas eram $100 \%$ válidas, ou seja, nas provas em que a dica informativa era apresentada, o participante poderia - e era instruído a fazê-lo - levar em conta apenas o estímulo indicado para sua decisão na tarefa de reconhecimento. Embora a dica informativa informasse sobre o estímulo relevante, não era preditiva em relação ao tipo de respostas (positiva, ou negativa), pois o estímulo teste poderia ser o estímulo indicado (resposta positiva), ou um estímulo não presente na cena memorizada.

Em cada bloco foram realizadas 60 provas, 15 provas para cada um dos quatro tratamentos resultantes da combinação de validade da dica (informativa e neutra) e tipo de prova (resposta positiva, resposta negativa). No 
início de cada bloco foram realizadas 10 provas de treino. A ordem de apresentação dos blocos foi randomizada entre os sujeitos.

\section{Resultados}

O índice de discriminação d' (Snodgrass \& Corwin, 1988) foi utilizado para medir o desempenho neste estudo. O índice d', definido pela distância entre as médias das distribuições do item associado à resposta positiva ("sim", "estava na cena memorizada") e à resposta negativa ("não", "não estava na cena memorizada"), foi calculado como d' = z(taxa de acertos "sim") - z(taxa de erros "não"). Os índices obtidos (Figura 2A) foram submetidos a uma análise de variância para medidas repetidas considerando os fatores validade da dica (informativa, neutra), tipo de dica (espacial, visual), tarefa de reconhecimento (cor, forma). Essa análise mostra que, nas provas com dicas informativas, o d' ( $M=$ $2,03, E P M=0,17)$ é superior àqueles obtidos nas provas com dicas neutras $(M=1,72$, EPM $=0,20)(F(1,13)=5,43$, $\left.p=0,037, \eta_{\mathrm{p}}^{2}=0,29\right)$. O desempenho é melhor nas provas com dicas espaciais ( $M=2,29, E P M=0,17)$ do que nas provas com dicas visuais $(M=1,46, \mathrm{EPM}=0,21)(F(1,13)$ $\left.=27,63, p<0,001, \eta^{2}=0,68\right)$. O índice de discriminação também foi maior na tarefa de reconhecimento de cores $(M=2,16, E P M=0,18)$ do que no reconhecimento de formas $(M=1,60$, EPM $=0,20)(F(1,13)=19,12, p=$ 0,$\left.001 ; \eta_{p}^{2}=0,60\right)$. A interação entre validade e tipo da dica $\left(F(1,13)=7,43, p=0,017, \eta_{p}^{2}=0,36\right)$ mostra que o índice de discriminação na presença da dica informativa é maior do que nas provas de dicas neutras apenas quando a dica é do tipo espacial ( $p=0,005)$, e não quando ela é visual $(p=0,985)$. A interação tripla envolvendo os três fatores manipulados permite isolar de forma mais específica o efeito da validade da dica apenas nas provas com dicas espaciais na tarefa de reconhecimento de cor $\left(F(1,13)=8,03, p=0,014, \eta_{p}^{2}=0,38\right)$.

As médias dos tempos de respostas corretas de cada participante, sem levar em conta os TRs menores do 250 ms e maiores do que $5000 \mathrm{~ms}$ em cada tratamento (Figura 2B), foram submetidas a uma análise de variância para medidas repetidas considerando os fatores validade da dica (informativa, neutra), tipo de dica (espacial, visual), tarefa de reconhecimento (cor, forma). Essa análise mostra que a média dos TRs é menor nas provas com dicas informativas ( $M=733 \mathrm{~ms}$, $E P M=35 \mathrm{~ms}$ ) do que nas provas com dicas neutras $(M=965 \mathrm{~ms}$, EPM $=$ 41ms) $\left(F(1,13)=44,83, p<0,001 ; \eta^{2}=0,78\right)$. O TR varia em função do tipo de dica, sendo que as respostas são mais rápidas nas provas com dicas espaciais ( $M=781 \mathrm{~ms}$, $E P M=33 \mathrm{~ms}$ ) do que nas provas com dicas visuais $(M=$ $917 \mathrm{~ms}, \mathrm{EPM}=43 \mathrm{~ms})\left(F(1,13)=15,50, p=0,002, \eta_{p}^{2}=\right.$ $0,54)$. O TR é menor nas provas de reconhecimento de cor $(M=795 \mathrm{~ms}, E P M=29 \mathrm{~ms})$ do que nas provas com reconhecimento de forma $(M=903 \mathrm{~ms}$, $E P M=42 \mathrm{~ms}$ ) $\left(F(1,13)=21,26, p<0,001, \eta_{p}^{2}=0,62\right)$. Existe também uma interação significativa entre o tipo e a validade da
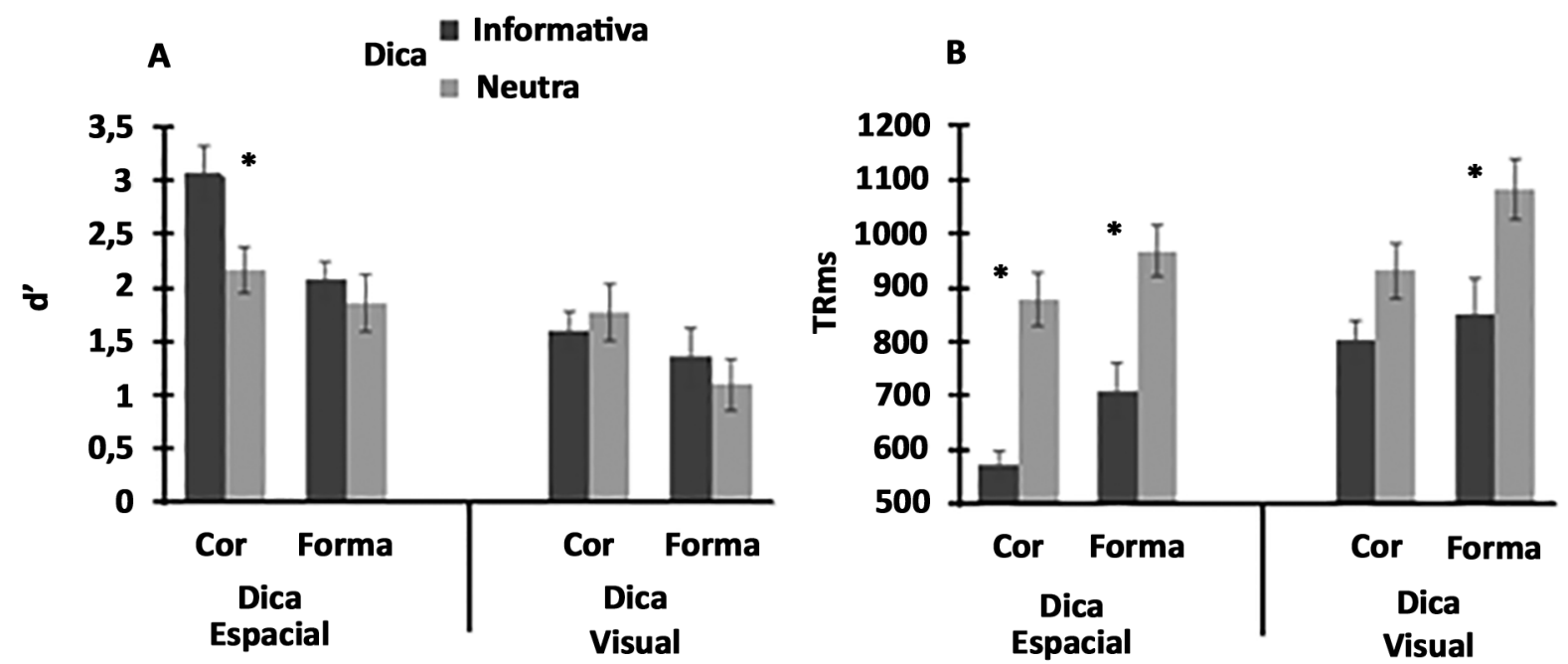

Figura 2. Médias dos Índices de Discriminação (2A) e dos Tempos de Resposta (2B) em Função do Tipo de Dica (Espacial, Visual), da Validade das Dicas (Informativa, Neutra) nas Tarefas de Reconhecimento de Cor e de Forma. Erro Padrão das Estimativas Apresentado nos Segmentos Verticais ( ${ }^{*}$ ) $\left.p<0,01\right)$. 
dica $\left(F(1,13)=4,90, p=0,045, \eta_{p}^{2}=0,27\right)$, que reflete uma vantagem maior, de $282 \mathrm{~ms}$, proporcionada pela dica válida espacial, quando comparada com a vantagem de $180 \mathrm{~ms}$, proporcionada pela dica válida visual.

De maneira geral a análise do índice de discriminação d' e do TR são concordantes quantos aos efeitos principais. Os participantes são mais rápidos e precisos quando as dicas são espaciais do que quando são visuais, na tarefa de reconhecimento de cor do que no reconhecimento de forma e nas provas com dicas informativas do que nas provas com dicas neutras. $O$ TR parece ter sido mais sensível ao efeito das dicas informativas visuais do que o d', mas tanto o TR quanto o d' sugerem que nas provas com dicas espaciais o ganho proporcionado pela dica informativa é maior do que o proporcionado nas provas com dicas visuais.

\section{Discussão}

O paradigma de dicas retroativas tem mostrado que a orientação da atenção para regiões de uma representação armazenada na memória visual de curto prazo proporciona um ganho no desempenho em tarefas de reconhecimento. Este ganho tem sido interpretado como decorrente de um processo de priorização da informação na região apontada pela dica (Gazzaley \& Nobre, 2012) ou como decorrente da recuperação dessa informação memorizada na memória de trabalho para um estado ativo que permitiria um processo de comparação mais eficiente em tarefas e reconhecimento (Griffin \& Nobre, 2003; Lepsien \& Nobre, 2006). Neste estudo investigamos a contribuição de dicas retroativas espaciais e visuais para o desempenho numa tarefa de reconhecimento de itens. Nossos resultados mostram que saber de antemão a localização do estímulo que contém a característica relevante para a tarefa de reconhecimento proporciona um ganho significativo nessa tarefa, tanto em termos da capacidade de discriminação como em termos do tempo necessário à emissão da resposta. Este resultado corrobora a literatura existente quanto ao desempenho em tarefas de reconhecimento de cores (Griffin \& Nobre, 2003; Li \& Saiki, 2015). Entretanto, saber de antemão a localização do estímulo é inócuo quando a dimensão relevante a ser testada é a forma do objeto memorizado. Ou seja, a dica retroativa espacial parece permitir a recuperação da cor, mas não da forma do objeto memorizado.

Em comparação com a informação proporcionada pela dica retroativa espacial, a dica retroativa visual não interfere no desempenho da tarefa de reconhecimento. Estes resultados sugerem que a informação sobre a localização do objeto é mais importante para sua recuperação do que informações sobre suas características visuais. Essa supremacia da informação espacial está presente em várias teorias sobre a conjunção da informação visual. Na teoria de integração de características (Treisman \& Gelade, 1980) o espaço é a dimensão que permite agrupar num objeto coerente as características visuais codificadas em diferentes mapas corticais. A atenção focalizada numa determinada região do espaço permite que as características relacionadas àquela região sejam agrupadas e integradas num objeto coerente. Nossos resultados sugerem que a informação armazenada na memória de trabalho visual também pode ser recuperada de forma eficiente se a atenção é dirigida para a localização ocupada previamente pela informação relevante. No entanto, o processo de recuperação de uma característica visual baseada em outra característica visual do objeto não tem o mesmo grau de eficiência. Resultados semelhantes já foram apontados por Nissen (1985, citado em Baddeley \& Hitch, 1994, p. 489).

Além da vantagem das dicas espaciais em relação às dicas visuais, outro aspecto que deve ser considerado na avaliação dos resultados deste estudo diz respeito às diferenças encontradas no desempenho das tarefas de reconhecimento da cor e da forma. Este aspecto deve ser considerado tanto do ponto de vista do efeito da dica espacial para as tarefas de reconhecimento de cor e de forma, como de maneira geral, da facilidade relativa do reconhecimento da cor em relação ao reconhecimento da forma. Nossos resultados mostram que o desempenho na tarefa de reconhecimento foi melhor quando os participantes deveriam reconhecer a cor do que quando deveriam reconhecer a forma dos objetos. Esse é um dado comum na literatura (ver, por exemplo, Allen, Baddeley, \& Hitch, 2006), e pode ser explicado pela discriminabilidade relativa mais difícil das formas em relação à das cores utilizadas. $O$ outro aspecto diz respeito à ineficácia da dica espacial na tarefa de reconhecimento da forma. Mesmo com a dica espacial, que tem se mostrado eficiente na recuperação da cor, a recuperação da forma baseada na informação espacial também não se mostrou eficiente. Este resultado está em conflito com resultados anteriores obtidos em nosso laboratório, em estudos com formas geométricas e com caracteres chineses (Ferreira et al., 2014; Galera \& Quinn, 2014). Nossa suposição é que a similaridade entre as 
formas utilizadas no presente estudo tenha interferido no processo de recuperação. Esta questão permanece por ser explorada.

Nossos resultados também sugerem que o paralelo existente entre os processos cognitivos envolvidos na orientação da atenção em tarefas com dicas espaciais preditivas e retroativas (Griffin \& Nobre, 2003; Lepsien $\&$ Nobre, 2006) parece não existir quando se trata de dicas retroativas baseadas em características visuais. A ausência do ganho proporcionado pelo conhecimento de uma das características do objeto (por exemplo, sua cor) para a recuperação de outra característica, por exemplo sua forma, parece conflitar com o processo de seleção da informação no ambiente visual baseado em características visuais (Carrasco, 2011; Maunsell \& Treue, 2006, Nakayama \& Martini, 2011) e deve ser explorado em estudos futuros.

Em termos da arquitetura da memória de trabalho, considerando que a dica retroativa espacial permite a recuperação da informação memorizada (Lepsien \& Nobre, 2006), a questão que se coloca é, então, sobre a estrutura para a qual é recuperada a informação. Nós temos trabalhado com a hipótese de que a informação é recuperada para um sistema no qual pode ser inspecionada de forma consciente, tal como uma imagem mental. De acordo com Logie (2011), a imagem mental é uma função do executivo central, e a representação visual seria recuperada para o foco da atenção, onde poderia ser inspecionada conscientemente. De fato, um dos estudos de nosso laboratório sugerem que o participante pode relatar se recuperou ou não a representação indicada, ou seja, o participante tem consciência do resultado do processo de recuperação (Pucci \& Galera, 2015). No entanto, outros estudos realizados em nosso laboratório têm mostrado que o processo de recuperação é afetado pela apresentação de uma informação visual irrelevante, o que sugere que a recuperação envolve um sistema sensível à informação visual. Nesse caso, seria difícil explicar como o executivo central, um sistema amodal, seria afetado pela informação visual irrelevante. Nós sugerimos que a informação visual é recuperada para um sistema de armazenamento visual que dá sustentação à representação visual enquanto esta é inspecionada (Galera \& Quinn, 2014).

O sistema que dá sustentação à representação recuperada da memória de trabalho visual é o buffer visual (Kosslyn et al., 2006). Nesse modelo, a janela atentiva pode selecionar regiões do buffer para processar em detalhes as informações ali referenciadas. Se a geração de uma imagem é necessária em uma tarefa, as informações necessárias para a geração dessa imagem - armazenadas no sistema de processamento das propriedades dos objetos - podem ser ativadas, gerando uma representação do objeto no buffer visual. De acordo com esta interpretação, o processo de recuperação da informação em função da atenção especial seria realizado através de uma modulação retinotópica, que levaria a uma reativação de regiões do córtex visual primário (áreas V1 - V4), tal como proposto por Kosslyn et al. (2006), por Damásio (1989), e demonstrado por Sligte, Scholte e Lamme (2009). A representação reativada, mantida em um estado ativo ou em um estado de ativação mais acentuado, permitiria um processo de comparação mais eficiente com a representação do estímulo teste.

Também é importante considerar que a diferença entre a recuperação da informação baseada nas dicas retroativas espacial e visual pode ser decorrente das diferenças existentes entre as duas tarefas. $\mathrm{Na}$ recuperação da informação baseada na dica espacial, o participante poderia memorizar apenas uma das dimensões do estímulo (ou a cor ou a forma), pois ambas foram manipuladas entre blocos de provas; no caso da recuperação baseada na dica retroativa visual (cor ou forma), o participante deveria memorizar a conjunção destas duas dimensões. Isto implica que as provas espaciais possuíam menor carga cognitiva, o que pode ter facilitado o desempenho dos participantes na tarefa. Embora em conflito com os resultados de Li e Saiki (2015), que encontraram efeitos mais pronunciados da dica retroativa com estímulos definidos pela conjunção de cor, forma e localização, esta questão deverá ser esclarecida em estudos subsequentes.

Para concluir, acreditamos que nosso estudo da recuperação da informação armazenada na memória de trabalho visual através de dicas retroativas é inovador, tanto em termos da aplicação de novas tarefas experimentais ao estudo da memória de trabalho, como em termos teóricos. Em termos teóricos nossos resultados reafirmam a prioridade da localização espacial em relação às características visuais e também apontam para uma possível assimetria no papel das características visuais nos processos envolvidos na seleção da informação no ambiente e na memória. A prioridade da localização espacial sobre as informações visuais sugere que, além de estar envolvida no processo de recitação da informação do visual cache (Logie, 2011), a atenção espacial pode também estar envolvida no processo de 
recuperação da informação armazenada nesse sistema de armazenamento.

\section{Referências}

Allen, R. J., Baddeley, A. D., \& Hitch, G. J. (2006). Is the binding of visual features in working memory resource-demanding? Journal of Experimental Psychology: General, 135(2), 298-313. doi: 10.1037/00963445.135.2.298

Albers, A. M., Kok, P., Toni, I., Dijkerman, H. C., \& Langue, F. P. (2013). Shared representations for working memory and mental imagery in early visual cortex. Current Biology, 23(15), 1427-1431. doi: 10.1016/j.cub.2013.05.065

Baddeley, A. D. (1986). Working memory. Oxford: Oxford University Press.

Baddeley, A. D. (2007). Working memory, thought, and action. Nova Iorque: Oxford University Press

Baddeley, A. D., \& Hitch, G. J. (1994). Developments in the concept of working memory. Neuropsychology, 8(4), 485-493. doi: 10.1037/0894-4105.8.4.485

Borst, G., Niven, E., \& Logie, R. H. (2012). Visual mental image generation does not overlap with visual short-term memory: a dual-task interference study. Memory and Cognition, 40(3), 360-372. doi: 10.3758/s13421-011-0151-7

Carrasco, M. (2011).Visual attention: the past 25 years. Vision Research, 51(13), 1484-1525. doi: 10.1016/j.visres.2011.04.012

Cowan, N. (2005). Working memory capacity. Hove, Inglaterra: Psychology Press.

Damasio, A. R. (1989). Time-locked multiregional retroactivation: a systems-level proposal for the neural substrates of recall and recognition. Cognition, 33(1-2), 25-62. doi:10.1016/0010-0277(89)90005-X

Ferreira, S; Pucci, I. W; \& Galera, C. A (2014, outubro). O buffer visual e a recuperação da informação visual da memória de trabalho. Pôster apresentado na $44^{\circ}$ Reunião Anual da Sociedade Brasileira de Psicologia, Ribeirão Preto. Resumo recuperado de http://www. sbponline.org.br/anais-e-resumos

Fougnie, D., \& Alvarez, G. A. (2011). Object features fail independently in visual working memory: evidence for a probabilistic feature-store model. Journal of Vision, 11(12), 10.1167/11.12.33. doi:10.1167/11.12.3

Galera, C., \& Quinn, G. (2014, julho). Visual buffer and retrieval of visual information from working memory. Comunicação apresentada em International Conference on Working Memory. Cambridge, UK.

Gazzaley, A., \& Nobre, A. C. (2012). Top-down modulation: bridging selective attention and working memory. Trends in Cognitive Sciences, 16(2), 129-135. doi: 10.1016/j.tics.2011.11.014

Griffin, I. C., \& Nobre, A. C. (2003). Orienting attention to locations in internal representations. Journal of Cognitive Neuroscience, 15(8), 1176-1194. doi: 10.1162/089892903322598139

Harrison, S. A., \& Tong, F. (2009). Decoding reveals the contents of visual working memory in early visual areas. Nature, 458 (7238), 632-635. doi: $10.1038 /$ nature 07832 .

Kondo, A.; \& Saiki, J. (2012). Feature-specific encoding flexibility in visual working memory. PLOS ONE, 7(12). doi: 10.1371/journal. pone.0050962

Kosslyn, S. M. (1994). Image and brain: the resolution of the imagery debate. Cambridge, MA: MIT Press.
Kosslyn, S. M., Ganis, G., \& Thompson, W. L. (2001). Neural foundations of imagery. Nature Reviews Neuroscience, 2, 636-642. doi: $10.1038 / 35090055$

Kosslyn, S. M., Thompson, W. L., \& Ganis, G. (2006). The case for mental imagery. Nova lorque: Oxford University Press.

Lepsien, J., \& Nobre, A. (2006). Cognitive control of attention in the human brain: Insights from orienting attention to mental representations. Brain Research, 1105, 20-31. doi:10.1016/j. brainres.2006.03.033

Lepsien, J., Thornton, I., \& Nobre, A. C. (2011). Modulation of working-memory maintenance by directed attention. Neuropsychologia, 49 , 1569-1577. doi:10.1016/j.neuropsychologia.2011.03.011

Li, Q., \& Saiki, J. (2015). Different effects of color-based and location-based selection on visual working memory. Attention, Perception \& Psychophysics, 77(2), 450-463. doi: 10.3758/s13414-014-0775-3

Logie, R. H. (1995).Visuo-spatial working memory. Hove: Lawrence Erlbaum Associates Ltd

Logie, R. H. (2003). Spatial and visual working memory: a mental workspace. In D. Irwin \& B. Ross (Orgs.), Cognitive vision: the psychology of learning and motivation (pp. 37-78). Nova lorque: Elsevier Science.

Logie, R. H. (2011). The functional organization and capacity limits of working memory. Current Directions in Psychological Science, 20(4), 240-245. doi: $10.1177 / 0963721411415340$

Logie, R. H., \& Marchetti, C. (1991). Visuo-spatial working memory: visual, spatial or central executive? In R. H. Logie \& M. Denis (Orgs.), Mental images in human cognition (pp. 105-15). Amsterdam: Elsevier

Maunsell, J. H. R., \& Treue, S. (2006). Feature-based attention in visual cortex. Trends in Neuroscience, 29(6), 317-322. doi: 10.1016/j. tins.2006.04.001

Nakayama, K., \& Martini, P. (2011). Situating visual search. Vision Research, 51(13), 1526-1537. doi: 10.1016/j.visres.2010.09.003

Oberauer, K. (2003). Selective attention to elements in working memory. Experimental Psychology, 50(4), 257-269. doi: 10.1026//16183169.50.4.257

Pearson, D. G. (2001). Imagery and the visuo-spatial sketchpad. In J. Andrade (Org.), Working memory in perspective (pp. 33-59). Hove: Psychology Press.

Pertzov, Y., \& Husain, M. (2014). The privileged role of location in visual working memory. Attention, Perception and Psychophysics, 76, 1914-1924. doi: 10.3758/s13414-013-0541-y

Peters, B., Kaiser J., Rahm, B., \& Bledowski, C. (2015). Activity in human visual and parietal cortex reveals object-based attention in working memory. The Journal of Neuroscience, 35(8): 3360-3369. doi:10.1523/JNEUROSCI.3795-14.2015

Posner, M. I. (1980). Orienting of attention. The Quarterly Journal of EXperimental Psychology, 32, 3-25. doi: 10.1080/00335558008248231

Pucci, I. W., \& Galera, C. (2015, maio). Recuperação da informação da memória de trabalho visual: a necessidade de um buffer visual. Painel apresentado no $9^{\circ}$ Congresso Norte-Nordeste de Psicologia Salvador. Resumo recuperado de http://www.conpsi2015.com.br/

Quinn, J. G. (2012). Theories and debate in visuo-spatial working memory: the questions of access and rehearsal. In V. Gyselinck \& F. Pazzaglia (Orgs.), From mental imagery to spatial cogntion and language. Essays in honour of Michel Denis (pp. 106-123). Londres: Psychology Press. 
Quinn, J. G., \& McConnell, J. (1996). Indications of the functional distinction between the components of visual working memory. Psychologische Beitrage, 38(3-4), 355-367.

Sligte, I. G., Scholte, H. S., \& Lamme, V. A. F. (2009). V4 activity predicts the strength of visual short-term memory representations. The Journal of Neuroscience, 29(23), 7432-7438. doi:10.1523/JNEUROSCl.0784-09.2009

Snodgrass, J. G., \& Corwin J. (1988) Pragmatics of measuring recognition memory: applications to dementia and amnesia. Journal Experimental Psychology, 117(1), 34-50. doi:10.1037/0096-3445.117.1.34

\section{A. Galera, L. S. Guimarães, J. C. Rossini, J. J. R. A. Santana}

Sperling, G. (1960). The information available in brief visual presentations. Psychological Monographs, 74, 29-60. doi:10.1037/h0093759

Treisman, A. (1998). Feature binding, attention and object perception. Philosophical Transactions of the Royal Society B: Biological Sciences, 353(1373), 1295-1306. doi:10.1098/rstb.1998.0284

Treisman, A., \& Gelade, G. (1980). A feature-integration theory of attention. Cognitive Psychology. 12, 97-136. doi:10.1016/00100285(80)90005-5

Treisman, A., \& Gormican, S. (1988). Feature analysis in early vision: evidence from search asymmetries. Psychological Review, 95(1), 15. doi:10.1037/0033-295X.95.1.15

César Alexis Galera, Doutor em Psicologia Experimental pelo Instituto de Psicologia da Universidade de São Paulo, é Professor

Titular da Faculdade de Filosofia, Ciências e Letras de Ribeirão Preto, Universidade de São Paulo (FFCLRP - USP). Endereço para correspondência: Departamento de Psicologia - FFCLRP - USP.

Av. Bandeirantes 3900 - Ribeirão Preto - SP - CEP 14040-901.

Telefone/fax: 55(16)3315-3760. E-mail: algalera@usp.br

Luísa Superbia Guimarães, Graduanda em Psicologia e bolsista de Iniciação Científica no Laboratório de Psicologia Cognitiva pela Faculdade de Filosofia, Ciências e Letras de Ribeirão

Preto, Universidade de São Paulo (FFCLRP - USP). E-mail: luisa. guimaraes@usp.bre/ou luisa.superbia@gmail.com

Joaquim Carlos Rossini, Doutor em Ciências (Psicobiologia), pela Faculdade de Filosofia, Ciências e Letras de Ribeirão Preto, Universidade de São Paulo (FFCLRP/USP), é Professor do Instituto de Psicologia da Universidade Federal de Uberlândia (IPUFU).E-mail: jrossini@ufu.br

Jeanny Joana Rodrigues Alves de Santana, Doutora em Ciências (Psicobiologia), pela Faculdade de Filosofia, Ciências e Letras de Ribeirão Preto, Universidade de São Paulo (FFCLRP/USP), é Professora do Instituto de Psicologia da Universidade Federal de Uberlândia (IPUFU). E-mail: jeannysantana@yahoo.com.br 